\section{Extra-oral suction unit launched}

The OPTIMA EOS 350 device is designed for dental practices to effectively capture droplets and airborne aerosols from treatments. As an extra-oral suction unit, the device will help to ensure patient comfort during usage.

The OPTIMA EOS 350 unit has a triple layer HEPA H14 filter, which traps 99.995\% of particles that are $\geq 0.3 \mu \mathrm{m}$. The double UVC lamps positioned before the HEPA filter inactivates viruses and bacteria that are trapped by the filter. Through its Intelligent

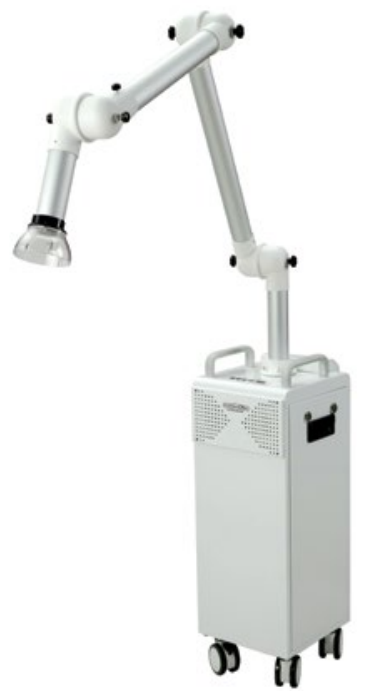

Airflow Dynamics, the exhaust air is released from a rear-mounted vent at the top of the system to prevent blow-up of any dust particles or contaminants from floor surfaces. The vent located at the rear enlarges comfort during treatment and circulates clean air in the room

Other features of the OPTIMA EOS 350 extra-oral suction unit are:

- Intelligent control panel with digital indicator and adjustable power levels

- Easy to disinfect and with an auto HEPA filter replacement reminder

- Optimised height for easy handling and lightweight design for easy moving between surgeries using ergonomically placed pull handles

- Airtight casing - prevents contaminants from escaping plus reduces noise

Quiet operation at $58 \mathrm{db}$ (air-conditioning volume) and silent wheels with minimal noise.

Available through Henry Schein Dental in the UK, for more information, visit: https://www.hsdequipment.co.uk/product/ optima-eos-350.

\section{Looking to optimise time and clinical outcomes?}

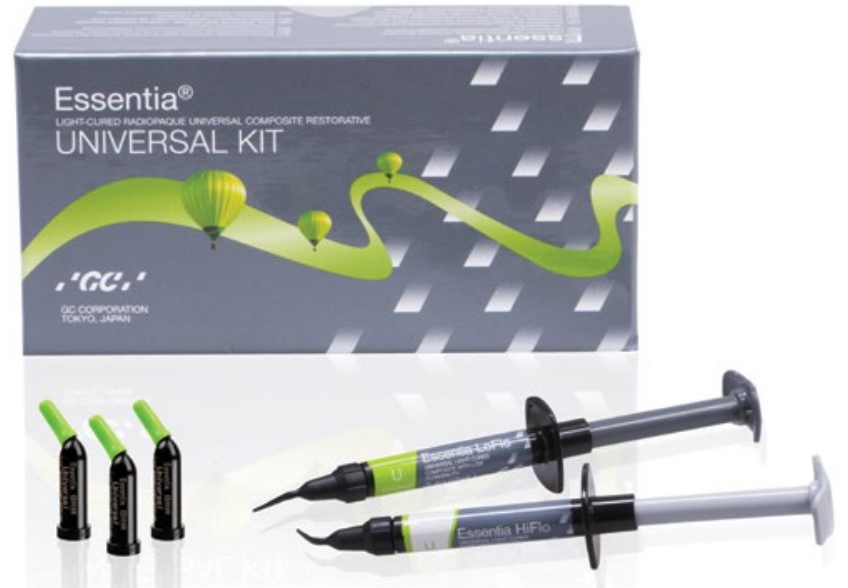

Look no further than everX Flow and

everX Flow's Bulk shade offers a depth Essentia Universal - tried and tested solutions for new clinical challenges. GC's quick and simple bulk fill alternatives to composite layering means you can provide patients with definitive restorations with a minimal amount of aerosol generation.

When failure is not an option, look to the strength of everX Flow, GC's bulk fill, fibrereinforced composite designed to replace dentine and improve fracture resistance of large restorations. Easy to apply, with two shades for every clinical need, everX Flow is the ideal choice for any restoration needing strength and to minimise shrinkage stress and it's also indicated to use as a core-build in weakened teeth.

everX Flow offers superior fracture toughness, close to that of dentine, for large durable restorations. This is due to the high amount of short glass fibres strongly bonded to the resin matrix. Its thixotropic viscosity allows it to flow and adapt perfectly to the cavity floor without slumping, even when placed in upper molars. cure of $5.5 \mathrm{~mm}$, ideal for deep posterior cavities and faster treatment times. The dentine shade has a higher opacity with a depth cure of $2 \mathrm{~mm}$ for highly aesthetic results and core build-up.

Is shade selection taking too long? Essentia Universal blends seamlessly with natural tooth structure in just one shade, regardless of the cavity shade. Available in three viscosities - strong enough for all cavity classes - it's the ultimate solution for posterior restorations.

Essentia Universal is non-sticky and easy to sculpt with great wettability and adaptation to tooth tissues. Easy to polish and packable for fast application, Essentia Universal offers excellent flexural strength and wear resistance.

For further information, get in touch with GC UK today to request a virtual meeting with one of the team to discuss GC's reduced AGP solutions. Contact GC UK Ltd on 01908 218999, email info.uk@gc.dental or visit www.gceurope.com.

\title{
Two decades of advances
}

This year marks the twentieth anniversary of the innovative Lisa steriliser from W\&H. Since its inception, Lisa has built an outstanding reputation for efficiency and ease-of-use.

As a highly robust unit, Lisa can complete a type B cycle in just 30 minutes and other cycles within only 13 minutes. With Lisa's intelligent EliTrace system, the sterilisation process can also be traced and documented down to individual instruments or kits, without any additional software or equipment.

The new Lisa steriliser brings together two decades of advances in a sleek, hygienic unit that enables you to continue complying with the most stringent regulatory requirements.

To find out more visit www.wh.com/en_uk, call 01727874990 or email office.uk@wh.com. 